\title{
Kualitas Air dan Indeks Pencemaran Danau Galela
}

\author{
Hendro Christi Suhry¹, Tri Retnaningsih Soeprobowati1,2, Tyas Rini Saraswati² dan \\ Jumari $^{2}$
}

${ }^{1}$ Departement Biologi, Fakultas Sains dan Matematika, Universitas Diponegoro

2Sekolah Pascasarjana, Universitas Diponegoro e-mail: trsoeprobowati@live.undip.ac.id

\begin{abstract}
ABSTRAK
Danau Galela adalah salah satu sumberdaya perairan tawar terbesar di Provinsi Maluku Utara. Seiring dengan pertambahan jumlah penduduk, Danau Galela mengalami permasalahan seperti penurunan kualitas air akibat meningkatnya sistem budidaya ikan dengan menggunakan keramba, perikanan tangkap dan objek wisata. Aktifitas yang dilakukan di badan air maupun daratan perlahan berpengaruh terhadap ekosistem danau. penelitian ini bertujuan untuk mengetahui kualitas air dan status pencemaran danau galela, berdasarkan parameter fisika, kimia dan biologi (Kelimpahan fitoplankton). Metode pengambilan sampel dilakukan dengan menggunakan purposive sampling. Sampel fitoplankton diambil dengan metode stratifikasi secara vertikal setiap $1 \mathrm{~m}$. selanjutnya data di analisis kelimpahan dan komposisi fitoplankton untuk menentukan indeks saprobic dan indeks pencemaran. Berdasaarkan hasil analisis kandungan Kadar fosfor, nitrit dan amonia pada beberapa stasiun melewati baku mutu perairan kelas I dan II. Komposisi fitoplankton di Danau Galela terdiri atas Chlorophyta 15 spesies, Bacillariophyta 10 spesies, Cyanophyta 4 spesies, Euglenophyta dan Pyrrhophyta 1 spesies. Berdasarkan kelimpahan fitoplankton diketahui bahwa perairan Danau Galela berkisar antara 10.089 ind/l hingga 32.108 ind/l, termasuk kategori mesoeutrofik hingga eutrofik. Indeks saprobik berkisar pada $\beta$ Mesosaprobik hingga $\alpha$ Mesosaprobik, sementara indeks pencemaran menunjukan memenuhi baku mutu hingga cemar ringan.
\end{abstract}

Kata kunci: Kualitas air, Pencemaran, Fitoplankton, Mesosaprobik

\begin{abstract}
Lake Galela is one of the largest freshwater resources in North Maluku Province. Along with the increase in population, Lake Galela has problems such as a decreasing water quality through improvement of the fish culture system using cages, aquaculture and tourist attractions. Activities carried out in water bodies and on land slowly affected the lake ecosystem. This study aims to determine the water quality and pollution status of Lake Galela, based on physical parameters, chemistry and biology. The sampling method is using purposive sampling. Phytoplankton sample were collected vertical stratification method every $1 \mathrm{~m}$. then the data were analyzed for phytoplankton abundance and composition to determine the saprobic index and pollution index. Based on the results of the analysis of phosphorus, nitrite and ammonia levels in several stations through the water quality standards of class I and II. Phytoplankton composition in Galela Lake consists of 15 species of Chlorophyta, 10 species of Bacillariophyta, 4 species of Cyanophyta, Euglenophyta and Pyrrhophyta 1 species. Based on the abundance of phytoplankton it is known that the waters of Lake Galela range from 10,089 ind / l to 32,108 ind / l, including the mesoeutrophic to eutrophic categories. Saprobic index ranges from $\beta$ Mesosaprobic to $\alpha$ Mesosaprobic, while the pollution index shows that it meets the quality standards to mild contamination.
\end{abstract}

Keywords: Water quality, Pollution, Phytoplankton, Mesosaprobic

Citation: Suhry, H., C., Soeprobbowati, T. R. dan Saraswati, T. R. (2020). Kualitas Air dan Indeks Pencemaran Danau Galela, 18(2), 236-241, doi:10.14710/jil.18.2.236-241

\section{Pendahuluan}

Danau adalah badan air pedalaman yang tidak memiliki pertukaran langsung dengan lautan. Ekosistem danau terdiri dari sifat fisik, kimia, dan biologis yang terkandung dalam badan air ini (Dembowska dan Józefowicz 2015; Dembowska dkk. 2015). Salah satu ekosistem danau yang ada di Indonesia adalah Danau Galela yang terletak di Maluku utara.

Danau Galela adalah danau terbesar di wilayah Galela dengan luas mencapai 250 ha, meliputi dua kecamatan, Kecamatan Galela dan Galela Barat. Danau ini dikelilingi 9 desa diantaranya Seki , Togawa, Sukonora, Igobula, Bale, Soatabaru, Dokolamo, Duma dan Goatalamo. Masyarakat lokal mengenal danau ini dengan beberapa sebutan diantaranya Danau Galela, Danau Tarakani atau Telaga Duma. Danau ini hanya memiliki satu aliran masuk ke danau yang hanya aktif pada musim hujan (inlet temporal) tanpa aliran keluar (outlet), sehingga air yang tertahan dalam Danau Galela relatif lebih lama dibandingkan danau lainnya (Abdulla, 2005). 
Danau ini dimanfaatkan oleh masyarakat sekitar untuk budidaya ikan menggunakan keramba. Perkembangan budidaya mengalami peningkatan yang sangat intensif dari 2 keramba pada tahun 2017 menjadi 206 keramba pada tahun 2018. Semakin banyak kegiatan di badan air dapat mengganggu kualitas perairan. Selain masalah tersebut Populasi penduduk yang terus meningkat, urbanisasi dan modernisasi menimbulkan masalah terutama pembuangan limbah ke dalam perairan yang menyebabkan penurunan kualitas air. Danau Galela terindikasi memiliki masalah eutrofikasi, dapat dikatakan demikian karena secara visual sebagian besar permukaan danau Galela tertutupi tumbuhan air eceng gondok. (Hull et al., 2010)

Penurunan kualitas perairan dapat menyebabkan ketidakstabilan dalam ekosistem, tingginya kandungan limbah organik yang tinggi akan berpengaruh terhadap kandungan fosfor yang ada di peraran. Salah satu efek yang dapat ditimbulkan dari tingginya fosfor diperairan adalah meningkatnya pertumbuhan tanaman air terutama enceng gondok (Mylaparavu, 2008). Masalah mengenai pencemaran air menjadi perhatian khusus karena apabila kandungan yang terdapat pada limbah melebihi baku mutu dapat menyebabkan keracunan kronis (Napiórkowska-Krzebietke 2015; Napiórkowska Krzebietke and Dunalska 2015). Baku mutu kualitas perairan terdiri dari parameter fisika dan kimia seperti BOD, suhu, konduktivitas listrik, nitrat, fosfor, kalium, oksigen terlarut, dan Logam berat seperti $\mathrm{Pb}$, $\mathrm{Cr}, \mathrm{Fe}, \mathrm{Hg}$, dll. Pencemaran sumber daya air dan hilangnya biodiversitas merupakan masalah serius dalam ekosistem. (Yilmaz et al., 2018).

Penelitian ini bertujuan untuk mengetahui kualitas air di danau galela berdasarkan komposisi fitoplankton. Penelitan menggunakan fitoplankton sebagai bioindikator telah lama berkembang sejak tahun 90an, karakteristik spesies dan struktur komunitas fitoplankton yang dikombinasikan dengan faktor kimia dan fisika air telah diterima secara umum sebagai indikator penilaian lingkungan (Guo, 1997). Fitoplankton dipilih karena merupakan agen bioindikator yang baik (Mize et al., 2008; Lei et al., 2010). Bioindikator adalah spesies atau komunitas tertentu, dengan keberadaannya dapat memberikan informasi fisik dan kimia lingkungan di tempat tertentu (Bellinger \& Sigee, 2010)

Fitoplankton memiliki kelebihan sebagai agen bioindikator apabila dibandingkan dengan organisme yang lain karena komunitas fitoplankton peka terhadap perubahan lingkungan mereka dan karenanya total biomassa fitoplankton dan banyak spesies fitoplankton digunakan sebagai indikator kualitas air (Reynolds 1997, Reynolds et al. 2002, Brettum dan Andersen 2005). Selain itu, ia bereaksi dengan cepat terhadap perubahan kondisi lingkungan (Tunowski, 2012).

\section{Study Area}

Danau Galela adalah danau terbesar di kepulauan Maluku Utara, menempati posisi ketinggian $23 \mathrm{mdpl}$ Danau Galela terletak pada koordinat 149'6.05 LU dan $127^{\circ} 48^{\prime} 38.46$ BT. Keberadaan Danau Galela meliputi 13 desa yang termasuk dalam dua kecamatan di kabupaten Halmahera Utara diantaranya Galela Selatan dan Galela Barat.

Penentuan titik sampling untuk pengambilan sampel air berdasarkan lokasi pemanfaatan daerah tangkapan air di Danau Galela (Purposive sampling). Titik sampling untuk pengamatan kualitas air ditentukan mewakili kondisi dan kegunaan badan air, yaitu untuk area referensi atau area yang tidak terpengaruh oleh kegiatan manusia, inlet, di sekitar area pertanian atau perkebunan dan area budidaya berbasis keramba (Gambar 1) secara stratifikasi vertikal dari permukaan $20 \mathrm{~cm}$, selanjutnya per-meter hingga bagian terdalam danau yaitu pada kedalaman 20 meter. Setelah sampel didapatkan di fiksasi dengan menggunakan larutan fiksasi yaitu formalin 4\%, hasil identifikasi fitoplankton kemudian dianalisis keanekaragaman dan kelimpahan dengan menggunakan software PAST. Indeks saprobik (Saprobic index) dapat dihitung dengan menggunakan rumus sebagai berikut: Indeks Saprobik plankton (X) (Dresscher \& Mark,1976):

$\mathrm{X}=(\mathrm{C}+3 \mathrm{D}-\mathrm{B}-3 \mathrm{~A}) /(\mathrm{A}+\mathrm{B}+\mathrm{C}+\mathrm{D})$

Keterangan :

$\mathrm{X}=$ koefisien saprobik (berkisar antara antara $-3 \mathrm{~s} / \mathrm{d}$ 3)

A = kelompok organisme Cyanophyta

$\mathrm{B}=$ kelompok organisme Euglenophyta

$\mathrm{C}=$ kelompok organisme Chlorophyta

$\mathrm{D}=$ Kelompok organisme Chrysophyta.

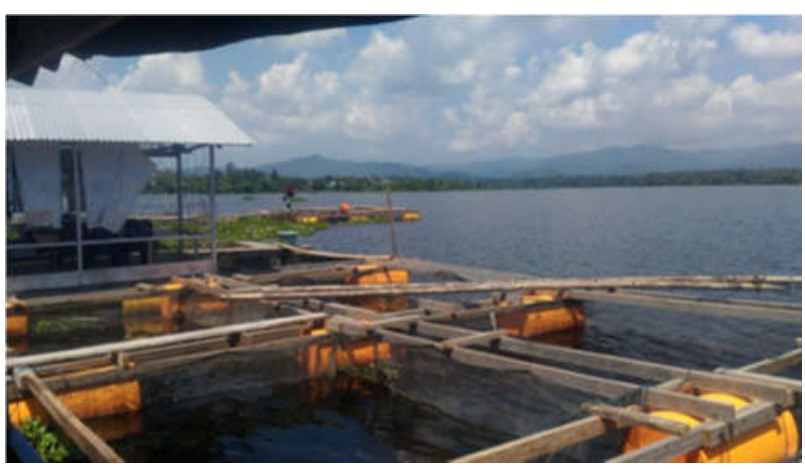

Gambar 1. Lokasi budidaya keramba

\section{Hasil dan Pembahasan}

Hasil pengukuran suhu pada permukaan di keempat stasiun relatif sama, akan tetapi lebih bervariasi pada stasiun 1 karena merupakan daerah referensi dengan kedalaman yang lebih jika dibandingkan dengan stasiun lainnya. Nilai kecerahan dari seluruh stasiun pengamatan berkisar antara 1-4 m. Kecerahan tertinggi ditemukan pada stasiun 1 mencapai $4 \mathrm{~m}$. Sedangkan kecerahan terendah pada stasiun 2 yang menempati daerah inlet. Adanya perbedaan nilai kecerahan ini diduga karena pengaruh dari kuantitas maupun kualitas air dari 
daerah aliran sungai yang membawa partikel-partikel bahan organik ke perairan danau.

Oksigen terlarut (DO) tertinggi terdapat pada stasiun 2 yang sebesar $6,29 \mathrm{mg} / \mathrm{lt}$, stasiun 2 berada di sungai yang perairannya bergerak turbulen sehingga memungkinkan terjadinya reoksigenase. Berdasarkan hasil pengukuran kadar DO pada stasiun 1 dan stasiun 3 lebih rendah dibandingkan daerah inlet disebabkan perairan danau pergerakannya laminir. Nilai oksigen terlarut terendah ditemukann pada stasiun 4 yang adalah area budidaya berbasis keramba. Rendahnya nilai oksigen terlarut di area budidaya diduga disebabkan karena adanya aktivitas keramba.

Sebaran vertikal DO rata-rata di danau Galela disajikan pada Gambar 2. Nilai DO di permukaan cenderung lebih tinggi dibandingkan bagian dasar perairan, Hal ini sejalan dengan Adiwilaga et al (2009) yang menyatakan suplai oksigen di lapisan permukaan lebih dominan diperoleh dari proses fotosintesis, difusi serta aliran yang memasuki badan perairan

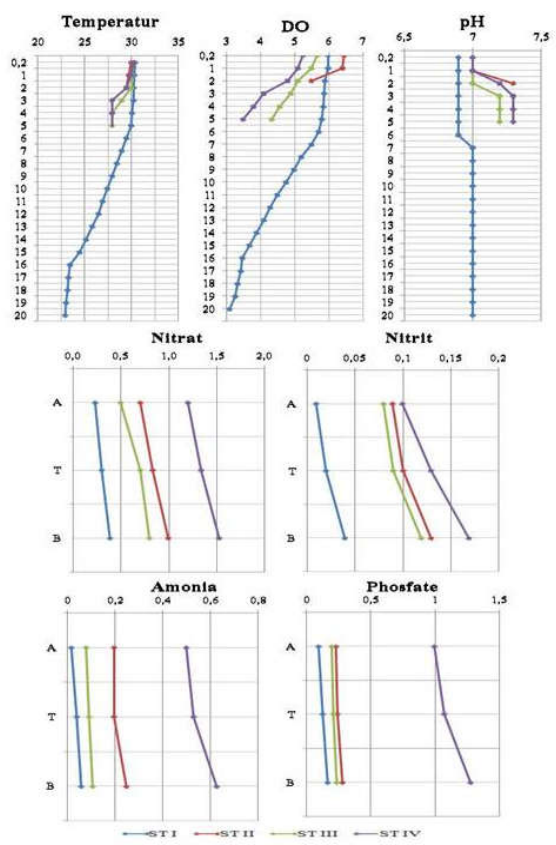

Gambar 2. Stratigrafi Temperatur, DO, Ph, Amonia, Nitrat, Nitrit, Phospate

Danau Galela menunjukan bahwa perairan berada pada kisaran basa. Nitrat $\left(\mathrm{NO}_{3}-\mathrm{N}\right)$ di stasiun IV cenderung lebih besar daripada stasiun lainnya. Kandungan Nitrat pada tiap stasiun masi memenuhi baku mutu kelas I. Nitrit pada masing-masing stasiun diketahui stasiun I memenuhi baku mutu kelas 1 berdasarkan PP RI No. 82 tahun 2001 tentang Pengelolaan Kualitas Air. Berbeda dengan kadar nitrit pada stasiun II, III dan IV yang melewati baku mutu kelas I an II. Hal ini disebapkan oleh buangan limba rumah tangga, pertanian dan aktifitas keramba yang menyebapkan kadar nitrit menjadi
meningkat.Konsentrasi nitritdalam keadaan seperti ini menunjukkan tingkat kesuburan eutrofik (AlvarezVazquez et al. 2014).

Amonia pada perairan Danau Galela berkisar antara 0,02-0,63 mg/l, stasiun I, II dan III masih memenuhi Berdasarkan baku mutu air kelas 1 yang mensyaratkan kandungan amonia maksimal 0,5 mg/l, sedangkan stasiun IV memenuhi baku mutu kelas II, Perairan Danau Galela pada stasiun IV tidak layak dipergunakan sebagai sumber baku air minum. Kadar amonia yang tinggi pada stasiun IV dikarenakan terus menerus menumpuknya limbah budidaya keramba

Fosfor pada perairan Danau Galela diketahui berkisar antara 0,1 hingga 1,28. Kandungan fosfor stasiun I diketahui memenuhi baku mutu kualitas air kelas I, berbeda degaan stasiun II, III dan IV yang melewati baku mutu kelas I dan II.

Tingginya beban masukan $\mathrm{P}$ yang berasal dari limbah domestik di Danau Galela dapat disebabkan oleh banyaknya peruntukan seiring dengan pertumbuhan jumlah penduduk yang tinggal di sekitar perairan danau. Populasi penduduk yang tinggi dibaringi dengan banyaknya kegiatan di area badan air akan meningkatkan beban masukan unsur hara di perairan. Hal ini dapat nyata terlihat dari populasi tumbuhan eceng gondok yang tumbuh di sekitar area keramba, tempat mencuci pakaian dan muara inlet. Zubcov et al (2015) mengungkapkan bahwa $\mathrm{N}$ dan $\mathrm{P}$ merupakan faktor utama yang mempengaruhi tingkat eutrofikasi di danau. (Wijoprionoet al, 2010).

Berdasarkan hasil penelitian didapat 31 spesies fitoplankton yang terbagi atas lima Divisi, masingmasing Chlorophyta adalah devisi yang paling dominan dengan 15 spesies, diikuti Bacillariophyta 10 spesies, Cyanophyta 4 spesies, Euglenophyta dan Pyrrhophyta masing-masing 1 spesies (Tabel 1)

Spesies Fitoplankton yang dapat ditemukan di seluruh stasiun adalah Aulacoseira granulata,Synedra ulna, Melosira varians, Mougeotia virescens, Aphanocapsa sp. dan Peridinium cinctum. Menurut Soeprobowati (2011), keberadaan fitoplankton jenis Aulacoseira mengindikasikan kondisi perairan hipereutrofik. Sehingga secara umum perairan Danau Galela telah berada pada status eutrofik menuju hipereutrofik.

Pada stasiun referensi (Stasiun I), kemelimpahan fitoplankton totalnya 32.108 ind/l. Fitoplankton stasiun referensi lebih tinggi dibandingkan pada stasiun karamba (18.627 ind/l), diikuti stasiun perkebunan 16.880 ind/l dan terendah pada stasiun inlet 10.089 ind/l. Fitoplankton stasiun karamba lebih rendah jika dibandingkan dengan stasiun referensi dikarenakan termakan oleh ikan budidaya sehingga kemelimpahannya menjadi berkurang. Jenis fitoplankton yang menjadi pakan alami ikan buidaya Danau Galela salah satunya adalah Navicula $s p$ (Abdulla, 2005). 
Tabel 1. Komposisi Fitoplankton di Danau Galela

\begin{tabular}{|c|c|c|c|c|c|}
\hline \multirow{2}{*}{ Divisi } & \multirow{2}{*}{ Spesies } & \multicolumn{4}{|c|}{ Satasiun } \\
\hline & & $\mathrm{I}$ & II & III & IV \\
\hline \multirow{15}{*}{ Chlorophyta } & Chlorococcus sp. & $\checkmark$ & - & $\checkmark$ & - \\
\hline & Closterium sp. & $\checkmark$ & - & - & $\checkmark$ \\
\hline & Coelastrum okular & $\checkmark$ & - & $\checkmark$ & - \\
\hline & Cosmarium $s p$ & $\checkmark$ & - & - & - \\
\hline & Crucigenia quardata & - & $\checkmark$ & - & $\checkmark$ \\
\hline & Glococystis sp. & $\checkmark$ & $\checkmark$ & $\checkmark$ & - \\
\hline & Kirchneriella lunaris & - & $\checkmark$ & $\checkmark$ & - \\
\hline & Mougeotia virescens & $\checkmark$ & $\checkmark$ & $\checkmark$ & $\checkmark$ \\
\hline & Oocystis sp & $\checkmark$ & - & $\checkmark$ & $\checkmark$ \\
\hline & Quadriqula sp & $\checkmark$ & - & - & $\checkmark$ \\
\hline & Selenastrum capricornutum & $\checkmark$ & - & - & - \\
\hline & Staurastrumsp. & $\checkmark$ & - & - & - \\
\hline & Tetraedron sp. & $\checkmark$ & $\checkmark$ & $\checkmark$ & - \\
\hline & Ulohtrixsp. & $\checkmark$ & - & - & - \\
\hline & Haematococcuspluvialis & $\checkmark$ & - & $\checkmark$ & $\checkmark$ \\
\hline \multirow{10}{*}{ Bacillariophya } & Aulacoseira granulata & $\checkmark$ & $\checkmark$ & $\checkmark$ & $\checkmark$ \\
\hline & Cocconeis sp. & $\checkmark$ & - & - & - \\
\hline & Cymbellasp. & - & $\checkmark$ & - & - \\
\hline & Fragilariasp. & - & $\checkmark$ & - & - \\
\hline & Surirella sp. & - & $\checkmark$ & - & $\checkmark$ \\
\hline & Melosira varians & $\checkmark$ & $\checkmark$ & $\checkmark$ & $\checkmark$ \\
\hline & Navicula sp. & $\checkmark$ & $\checkmark$ & $\checkmark$ & - \\
\hline & Nitzschia sp & - & $\checkmark$ & $\checkmark$ & $\checkmark$ \\
\hline & Synedra ulna & $\checkmark$ & $\checkmark$ & $\checkmark$ & $\checkmark$ \\
\hline & Synedra acus & - & $\checkmark$ & - & $\checkmark$ \\
\hline \multirow{4}{*}{ Cyanophyta } & Anabaena sp. & - & $\checkmark$ & $\checkmark$ & $\checkmark$ \\
\hline & Aphanocapsa sp. & $\checkmark$ & $\checkmark$ & $\checkmark$ & $\checkmark$ \\
\hline & Mycrocystis sp. & - & $\checkmark$ & - & $\checkmark$ \\
\hline & Oscillatoria limosa & $\checkmark$ & $\checkmark$ & $\checkmark$ & $\checkmark$ \\
\hline Euglenophyta & Euglena sp. & $\checkmark$ & $\checkmark$ & $\checkmark$ & $\checkmark$ \\
\hline Pyrrophyta & Peridinium cinctum & $\checkmark$ & $\checkmark$ & $\checkmark$ & $\checkmark$ \\
\hline
\end{tabular}

Pada stasiun inlet bagian permukaan didominasi oleh Synedra ulna diikuti Aphanocapsa sp. Aphanocapsa sp (Gambar 3) merupakan fitoplankton kelompok Cyanophyta Dominasi Cyanophyta pada suatu perairan dapat diindikasikan lewat visualisai air berwarna hiijau gelap (Fonge, 2012). Synedra ulna termasuk spesies yang toleran terhadap kandungan bahan organik yang tinggi dan banyak dijumpai di ekosistem danau maupun sungai. Stasiun perkebunan didominasi oleh Peridium cinctum diikuti oleh Synedra ulna dan Haematococcus pluvialis.

Indeks keanekaragaman menunjukan perairan Danau Galela memiliki indeks keanekaragaman berkisar antara 0,796 hingga 2,697. Nilai indeks keanekaragaman $0>\mathrm{H}<3$, dengan kata lain perairan Danau Galela memiliki nilai indeks keanekaragaman dalam kisaran rendah hingga sedang. Selaras dengan Odum (2005) mengungkapkan, dalam keaadaan seperti ini danau memiliki produktivitas cukup, kondisi ekosistem cukup seimbang, terindikasi telah terjadi tekanan ekologis sedang.

Hasil perhitungan nilai indeks saprobik, nilai indeks berkisar antara -0,1 sampai dengan 1, hal ini menunjukan tingkat pencemaran yang terjadi dikawasan perairan Danau Galela berkisar dari kategori ringan hingga cukup berat, atau pada fase $\beta$ Mesosaprobikhingga $\alpha$ mesosaprobik.
Stasiun dengan nilai indeks terendah adalah stasiun II, III dan IV pada fase $\alpha$ mesosaprobik , sedangkan stasiun I cenderung nilai indeks saprobik stabil pada fase $\beta$ meso saprobik. Kondisi ini disebapkan oleh masukan bahan organik dan anorganik, mengingat stasiun II merupakan daerah inlet yang melewati pemukiman warga, belum lagi ditambah erosi sepanjang sisi sungai. Stasiun III disebapkan oleh pembusukan sampah sisa perkebunan dan pembusukan eceng gondok ditambah aktifitas mencuci yang dilakukan masyarakat. Stasiun IV sangat rentan dikarenakan sisa pakan aktifitas budidaya, kematian ikan, selain itu stasiun IV paling dekat dengan pemukiman warga, ditambah aktifitas mencuci yang menyebapkan limba detergen masuk ke perairan.

Perhitungan indeks pencemaran dilakukan pada bagian permukaan danau, tengah dan bagian dasar perairan pada masing-masing stasiun, hasil yang didapat diketahui bahwa semakin dalam perairan Danau Galela, nilai indeks pencemaran semakin meningkat. Nilai indeks pencemaran tertinggi pada stasiun IV (Area budidaya), berkisar 3,3-3,7diikuti stasiun II daerah inlet, dengan nilai indeks pencemaran berkisar antara 1,3-1,44, kemudian stasiun III (Area perkebunan) dengan nilai indeks berkisar antara 1,12-1,41. Nilai indeks pencemaran 
terendah pada stasiun I dengan nilai indeks berkisar antara 0,72-0,86.

Kategori kualitas air berdasarkan nilai indeks pencemaran Danau Galela masing-masing stasiun menggambarkan rentang kualitas air memenuhi baku mutu hingga cemar ringan. Stasiun I dalam ketegori memenuhi baku mutu dikarenakan stasiun I merupakan area yang sulit dijangkau oleh masyarakat dengan kelerengan yang curam sehingga mempersulit masyarakat beraktifitas disekitar kawasan ini. Sedangkan stasiun II, III, dan IV dalam kategori tercemar ringan karena lebih dekat dengan aktifitas masyakat untuk pemenuhan kebutuhan

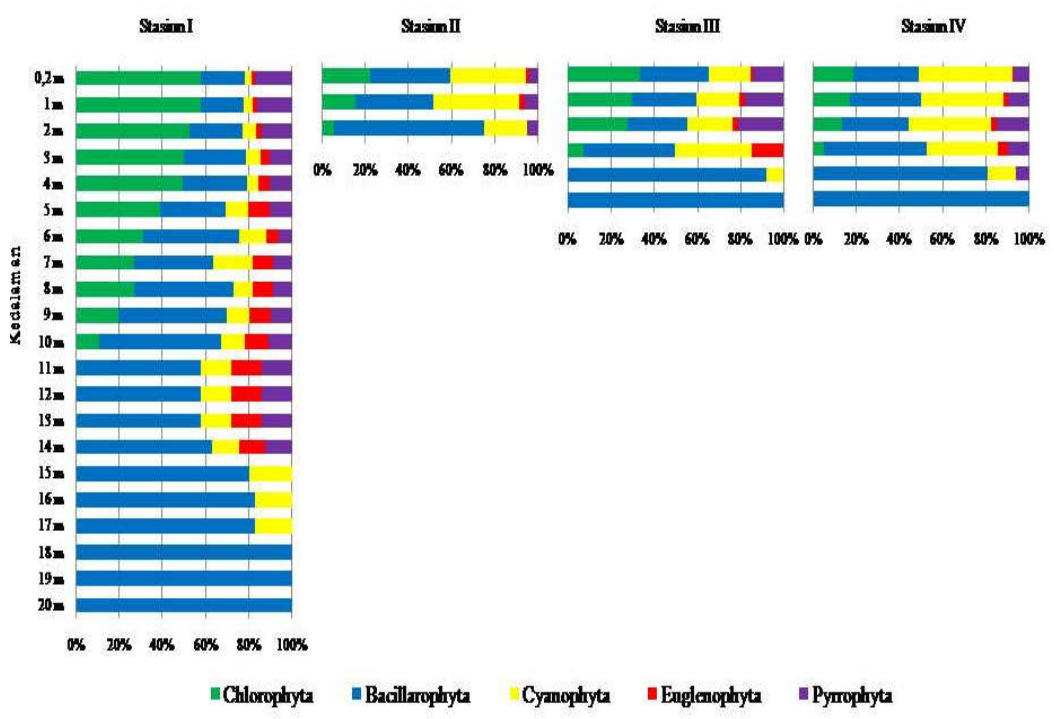

Gambar 3. Stratifikasi Fitoplankton pada tiap lokasi

\section{Kesimpulan}

Kualitas perairan Danau Galela ditinjau dari faktor fisik-kimia perairan memiliki nilai yang berfluktuatif sesuai dengan peruntukan disekitar masing-masing stasiun pengamatan. Kandungan fosfor dan nitrit pada perairan stasiun II, III dan IV tidak layak untuk bahan baku konsumsi demikian juga berdasarkan kadar amonia pada stasiun IV. Nilai indeks pencemaran Danau Galela ada pada kategori memenuhi baku-mutu hingga tercemar ringan. Komunitas fitoplankton pada perairan Danau Galela terdiri dari 5 devisi Cholophyta 12 spesies, Bacilariophyta 9 spesies, cyanophyta 4 spesies, euglenophyta 1 spesies dan dinophyta 1 spesies. Berdasarkan Kelimpahan dan keanekaragaman fitoplankton pada perairan Danau Galela mengindikasikan kualitas perairan Danau Galela mengalami tekanan ringan hingga sedang. Indeks saprobik perairan menempatkan Danau Galela berada pada kondisi tercemar ringan hingga sedang. 5.

\section{DAFTAR PUSTAKA}

Abdullah, A., 2005. Studi Bioekologi Ikan Air Tawar Di Danau Galela Kabupaten Halmahera Provinsi Maluku Utara, Bogor: Institut Pertanian Bogor

Adiwilaga, EM., Hariyadi, S dan Pratiwi. NTM., 2009. Perilaku Oksigen Terlarut Selama 24 Jam Pada Lokasi Keramba Jaring Apung di Waduk Saguling Jawa Barat. Jurnal Limnotek. 15(2):109-118.

Alvarez, VLJ., Fernandez, FJ., Martinez, A., 2014. Optimal control of eutrophication processes in a moving domain. Journal of the Franklin Institute. 351(8):412418.
Bellinger and Sigee. 2010. Freshwater Algae: Identification and Use as Bioindicators. John Wiley \& Sons,Ltd, West Sussex

Dembowska, E., Napiórkowski, P., Mieszczankin,T., Józefowicz, S., 2015. Planktonic indices in the evaluation of the ecological status and the trophic state of the longest lake in Poland. Ecological Indicators. 56:15-22. doi: 10.1016/j.ecolind.2015.03.019.

Dembowska,E., Józefowicz, S., 2015. Seasonal changes in phytoplankton and bioindices in the southern part of Lake Jeziorak (NE Poland) Oceanological \& Hydrobiological Studies. 44(1):1-10. doi: 10.1515/ohs-2015-0001.

Dresscher \& van der Mark. (1976). A simplified method for the biological assesment of the quality of fresh and slightly brackish water. Journal Hydrobiologia, 48(3), 199-201.

Fonge, BA., Tening, AS., Egbe, EA., Yinda, GS., Fongod, AN., Achu, RM, 2012. Phytoplankton diversity and abundance in Ndop wetland plain, Cameroon. Afr. Journal Environ Science and Technology. 6(6):247257.

Guo, PY., Lin,Z and Li, XY.1997. "Study on phytoplankton and evaluation of water quality in Dongping Lake," Transaction of Oceanology and Limnology, no. 4, pp. $37-42$

Hull, Kleywegt, S., Schroeder, J.,2015. Riskbased screening of selected contaminants in the Great Lakes Basin. J Great LakesRes 41(2015):238-245

Lei,YQ., Liang, AM., Zhu., 2010.“Phytoplankton and water quality in the Tongzhuang River of Three Gorges Reservoir," Journal of Lake Science, vol. 22, no. 2, pp. 195-200

Mize, SV and Demcheck, DK .2009."Water quality and phytoplankton communities in Lake Pontchartrain 
during and after the Bonnet Carré Spillway opening, April to October 2008, in Louisiana, USA," Geo-Marine Letters, vol. 29, no. 6, pp. 431-440

Mylaparavu, R., 2008. Impact of Phosphorus on Water Quality. University of Florida. Florida.

Napiórkowska-Krzebietke, A., 2015. Cyanobacterial bloom intensity in the ecologically relevant state of lakes - an approach to Water Framework Directive implementation. Oceanological and Hydrobiological Studies. 44(1):97-108.

Napiórkowska-Krzebietke, A., Dunalska, J., 2015. Phytoplankton-based recovery requirement for urban lakes in the implementation of the Water Framework Directive's ecological targets. Oceanological and Hydrobiological Studies.44(1):109-119.

Odum, E.P., 2005. Fundamentals of Ecology Philadelpia.Assessment of microcystins in lake water and the omnivorous. 4rd ed. W. B. Saunders Co.

Reynolds, CS. 1997 Vegetation Processes in the pelagic. A model for ecosystem theory. In: Kinne 0. (ed.), Excellence in ecology, Ecology Institute, Oldendorf/Luhe, Germany, pp 1-371
Reynolds,C., Huszar V., Kruk C., Naselli-Flores L. \& Melo S. 2002. Towards a functional classification of the freshwater phytoplankton. J. Plankton Res. 24:417-428

Soeprobowati, TR., 2011. komunitas fitoplangkton danau rawapening, Jurnal sains dan matematika, 19(1):1930

Tunowski, J. 2012. Pelagic zooplankton of Lake Dejguny with a population of marine relict Limnocalanus macrurus G.O. Sars, 1888. XXII Zjazd Hydrobiologów Polskich, Kraków, 19-22 IX 2012, pp. 187

Wijopriono., Purnomo, K., Kartamihardja, ES, Fahmi, Z, 2010. Fishery resources and ecology of TobaLake. Indonesian Fisheries Research Journal. 16(1): 714.

Yilmaz, N., Yardimci, C.H., Elhag, M., Dumitrache, C.A. 2018. Phytoplankton composition and Water Quality of Kamil Abdus lagoon (Tuzla lake), Istanbul-Turkey. water 10:603

Zubcov, E., Laurentia, U., Antoaneta, E., Nina, B and Natalia, B., 2009. Influence of nutrientsubstances on phytoplankton from Prut River, Annals of the University Dunarea de Jos of Galati, Fascicle II Mathematics, Physics,Theoretical Mechanics 1 (32): 68-72. 